\title{
Study of indications and post-operative complications of primary caesarean section in tertiary care hospital in Nepal
}

\author{
Sanyukta Rajbhandary ${ }^{1 *}$, Veena Rani Shrivastava ${ }^{2}$
}

\begin{abstract}
${ }^{1}$ Department of Obstetrics and Gynecology, B. P. Koirala Institute of Health Sciences, Dharan, Nepal
${ }^{2}$ Department of Obstetrics and Gynecology, Nepal Medical College and Teaching Hospital, Kathmandu, Nepal
\end{abstract}

Received: 03 February 2018

Accepted: 12 February 2018

\section{*Correspondence:}

Dr. Sanyukta Rajbhandary,

E-mail: sanyuktarb@gmail.com

Copyright: () the author(s), publisher and licensee Medip Academy. This is an open-access article distributed under the terms of the Creative Commons Attribution Non-Commercial License, which permits unrestricted non-commercial use, distribution, and reproduction in any medium, provided the original work is properly cited.

\begin{abstract}
Background: Caesarean section performed for appropriate obstetric or medical indications are life saving for both mother and new born. But its advantage does not justify its continuous increase as it is a major surgical procedure associated with maternal and fetal complications. The main objective of this study was to study the indications of primary caesarean section and its maternal and fetal complications in Nepal medical college teaching hospital (NMCTH).

Methods: This is a hospital based cross sectional study carried out for a period of one year from $1^{\text {st }}$ October 20113 to $30^{\text {th }}$ September 2014 in department of obstetrics and gynecology in NMCTH Nepal. The study included 183 primary caesarean cases enrolled as per the inclusion criteria. The indications for caesarean section, associated maternal and fetal complications were noted.

Results: The rate of caesarean section during the study period was $21.40 \%$. The study included 183 patients who underwent primary caesarean section, $162(88.5 \%)$ cases were emergency cases and $21(11.5 \%)$. Cases were elective cases. The most common indications were fetal distress $(n-74,40.4 \%)$ followed by cephalo pelvic disproportion (n$27,14.8 \%)$. The maternal complications seen were urinary tract infection (n-34, 68\%), wound infection (n-12, 24\%), post-partum hemorrhage $(\mathrm{n}-3,6 \%)$. The common fetal complications noted were apgar score of less than 7 (n-7, $31.8 \%)$, transient tachypnea of newborn (n-6, 27.27\%) and meconium aspiration syndrome (n-4, 18.18\%).

Conclusions: Emergency primary caesarean section was proportionally higher than elective caesarean section. It was also associated with more maternal and fetal complications.
\end{abstract}

Keywords: Complications, Fetal distress, Indication, Primary caesarean section

\section{INTRODUCTION}

The incidence of caesarean delivery is increasing worldwide. Several south Asian countries have recorded substantial increase in the caesarean section rates over the past decade. In Nepal the caesarean section rate rose from $1 \%$ in 2000 to $5 \%$ in 2011 ; in India it rose from $3 \%$ in 1992 to $11 \%$ in 2006 and in Bangladesh it rose from $2 \%$ in 2000 to $17 \%$ in $2011 . .^{1}$ The caesarean section rate in the tertiary hospitals in Nepal is 12 to $25 \%(2012) .^{2}$ The caesarean section rate in NMCTH was $22.30 \%$ in 2013 which has increased from $9.4 \%$ in 2002..$^{3,4}$ A World Health Organization (WHO) consensus conference 1992, states that no region should have a CS rate above 10$15 \% .^{5}$

Some of the factors that increase the rate of caesarean section are increased primary cesarean delivery rate, failed induction and increased use of induction of labor, decreased use of operative vaginal delivery, increased macrosomia and caesarean delivery for macrosomia, decline in vaginal breech delivery, increased repeat 
caesarean delivery rate and decreased use of vaginal birth after caesarean delivery. Other factors such as increasing maternal age, caesarean section done on maternal request and malpractice litigation concerns also contribute to the increase in rate of caesarean section. ${ }^{6}$

Caesarean section is associated with maternal and fetal complications. The maternal complications of caesarean section include anaesthesia related complication, hemorrhage, urinary tract and gastrointestinal injuries, thromboembolism and wound infection. ${ }^{7}$

Fetal complications include skin laceration, cephalhematoma, clavicular fracture, brachial plexopathy, skull fracture, facial nerve palsy and respiratory complications. ${ }^{8,9}$

Caesarean sections performed for appropriate medical or obstetric indications are life saving for mother and as well as the newborn. But the high prevalence of CS is not associated with improved perinatal outcome and it has risks for mother and the neonate. Caesarean section is associated with maternal and fetal morbidity and mortality, therefore it is important to prevent overuse of caesarean delivery especially primary caesarean delivery. Therefore, to reduce the high prevalence of CS, each case should be thoroughly evaluated to determine the possibility for vaginal delivery.

\section{METHODS}

A hospital based cross sectional study was conducted in department of obstetrics and gynecology, Nepal medical College Teaching Hospital (NMCTH). NMCTH is a tertiary and referral level hospital. The study included pregnant women who were undergoing caesarean section for the first time. Women who had previously undergone caesarean section, any uterine surgeries or hysterotomy were excluded from the study. The calculated sample size was 183 , and consecutive patients were taken. A pretest was conducted in 20 women prior to carrying out this study to test the feasibility and to find out any practical problems that might be encountered in the process of study. Modifications were made as per the findings of the pretesting.

Cases fulfilling the inclusion criteria were explained about the study and an informed consent was taken. Elective Cases were enrolled from the antenatal ward and emergency cases were enrolled from the labor room whenever caesarean section was decided.

Data was collected based on structured proforma covering the relevant aspects. Detailed history, demographic data was taken, and general examination and vitals examination was done and noted in the proforma. The patients antenatal examination investigations included investigations like complete blood count, blood grouping and typing, blood glucose level, viral serology HIV 1, 2, HBsAg, VDRL, urine routine examination, ultrasonography (USG) and cardiotocography (CTG). Obstetric examination was done which included abdominal examination, per speculum and per vaginal examination. On abdominal examination, height of uterus, lie, presentation and fetal heart sound were noted. On per vaginal examination, cervical effacement, dilatation, consistency, position, head station and membrane status were noted. All these findings were noted in the proforma.

The details of the operations such as type of caesarean section, indication of caesarean section, intraoperative complications and fetal outcome were noted in the proforma. Maternal complications were noted in terms of postpartum hemorrhage, urinary tract infection, wound infection and caesarean hysterectomy.

Fetal complications were noted in terms of birth Apgar score at 1 and 5 minutes, TTN, MAS, birth traumas, NICU admission and cause of admission, still birth and neonatal death. All patients were followed in the postoperative period till the time of discharge and any postoperative complications were noted.

After getting consent and meeting the inclusion criteria, the proposed proforma was filled.

\section{Statistical analysis}

Data were collected and entered in Microsoft Excel. For descriptive analysis, percentage, proportion, ratio, mean, median, standard deviation and interquartile range were calculated. Bar and pie charts were used for diagrammatic representation. Data was presented as the mean + standard deviation. Chi squared tests were used to test for statistical significance. $\mathrm{P}$ value was considered to be significant if $<0.05$. Analysis was done using SPSS software 16.

\section{RESULTS}

\section{General demographics}

The study was conducted for a period of 1 year from 1 st October 2013 to 30th September 2014. There were total of 2355 deliveries, of which 504 cases were delivered by caesarean section (21\%). Out of total number of CS 408 were primary caesarean section. Present study included a total of 183 patients.

A total of 162 women delivered by emergency caesarean section of them 105 were primigravida and 57 were multigravida. 21 women underwent elective caesarean section of which 12 were primigravida and 9 were multigravida.

The mean age of delivering females was $25.49+4.7$ years. There was not much difference in age among elective and emergency CS groups. The youngest women 
delivered by CS was 17 years and the oldest was 38 years.

Considering the mode of CS and the gestational age, 80 females had a period of gestation more than 40 weeks of whom 74 underwent emergency CS. Maximum number of patients who underwent elective CS had gestation age between 38-40 weeks

\section{Indications of primary caesarean section}

The most common overall indication for caesarean section was fetal distress (n-74, 40\%). Other common indications were cephalopelvic disproportion (n-27, $15 \%)$, breech presentation $(\mathrm{n}-19,10 \%)$ and non progress of labor (n-17, 9\%). Other indications for caesarean section are shown in the tables below (Table 1).

Most common indication among emergency group were fetal distress, cephalopelvic disproportion and nonprogress of labor.

The most common indication for elective Primary Cs was maternal request $(\mathrm{n}-7,33 \%, \mathrm{p} 0.001)$ followed by breech presentation $(\mathrm{n}-5,24 \%)$
Table 1: Distribution of study participants as per indication of caesarean section.

\begin{tabular}{|llll|}
\hline Indications & $\begin{array}{l}\text { Emergency } \\
\text { CS }\end{array}$ & $\begin{array}{l}\text { Elective } \\
\text { CS }\end{array}$ & Total \\
\hline Fetal distress & 74 & 0 & 74 \\
\hline $\begin{array}{l}\text { Cephalopelvic } \\
\text { disproportion }\end{array}$ & 27 & 0 & 27 \\
\hline Breech presentation & 14 & 5 & 19 \\
\hline $\begin{array}{l}\text { Non progress of } \\
\text { labor }\end{array}$ & 17 & 0 & 17 \\
\hline Oligohydraminos & 6 & 3 & 9 \\
\hline Maternal request & 0 & 7 & 7 \\
\hline $\begin{array}{l}\text { APH) Placenta } \\
\text { previa }\end{array}$ & 5 & 2 & 7 \\
\hline Pre-eclampsia & 4 & 2 & 6 \\
\hline Failed induction & 5 & 0 & 5 \\
\hline Cord prolapse & 3 & 0 & 3 \\
\hline Transverse lie & 2 & 1 & 3 \\
\hline Hydrocephalus & 2 & 0 & 2 \\
\hline IUGR & 2 & 0 & 2 \\
\hline Twin & 0 & 1 & 1 \\
\hline BOH & 1 & 0 & 1 \\
\hline Total & 162 & 21 & 183 \\
\hline
\end{tabular}

Table 2: Distribution of study participants according to common indications and category of caesarean section.

\begin{tabular}{|c|c|c|c|c|c|c|c|}
\hline Indications & Total & $\begin{array}{l}\text { Fetal } \\
\text { distress }\end{array}$ & CPD & Breech & $\begin{array}{l}\text { Non progress } \\
\text { of labor }\end{array}$ & Preeclampsia & $\begin{array}{l}\text { Maternal } \\
\text { request }\end{array}$ \\
\hline Emergency CS & 162 & $74(45.7 \%)$ & $27(16 \%)$ & $14(8.6 \%)$ & $17(10.49 \%)$ & $4(2.46 \%)$ & 0 \\
\hline Elective CS & 21 & 0 & 0 & $5(23.8 \%)$ & 0 & $2(9.52 \%)$ & $7(33.33 \%)$ \\
\hline Total & 183 & 74 & 27 & 19 & 17 & 6 & 7 \\
\hline $\mathrm{P}$ value & & 0.001 & 0.043 & 0.032 & 0.119 & 0.088 & 0.001 \\
\hline
\end{tabular}

Total of 19 caesarean section were performed for Breech presentation, 5 were elective and 14 were emergent. But
CS for breech presentation was seen proportionally higher in elective than emergency CS (p 0.032) (Table 2).

Table 3: Maternal complications and category of CS.

\begin{tabular}{|llllll|} 
Category of CS & Total & UTI & $\begin{array}{l}\text { Wound } \\
\text { infection }\end{array}$ & $\begin{array}{l}\text { Post partum } \\
\text { hemorraghe }\end{array}$ & $\begin{array}{l}\text { Caesearean } \\
\text { hysterectomy }\end{array}$ \\
\hline Emergency CS & 162 & $32(19.8 \%)$ & $11(6.8 \%)$ & $3(1.9 \%)$ & $1(0.6 \%)$ \\
\hline Elective CS & 21 & $2(9.5 \%)$ & $1(4.8 \%)$ & 0 & 0 \\
\hline Total & 183 & 34 & 12 & 3 & 1 \\
\hline P value & & 0.257 & 0.724 & 0.529 & 0.718 \\
\hline
\end{tabular}

\section{Maternal complications}

Maternal complications were seen in total of 50 cases, 47 of these cases were emergent CS group while only 3 patients in elective CS group suffered from complications but were not found to be statistically significant. Infective complication like urinary tract infection and wound infections were the common complications (Table 3). One interesting thing to note was all the elective cases had prior Antenatal visit while 36 patients (22\%) who 
underwent emergency CS did not have an antenatal visit during her pregnancy ( $\mathrm{p}-0.016)$.

\section{Fetal outcomes}

There were total of 22 cases who had neonatal complications, and all of these neonates delivered by emergency caesarean section.

Table 4: Neonatal complications.

\begin{tabular}{|l|l|}
\hline Neonatal complications & Frequency \\
\hline Meconium aspiration syndrome & 4 \\
\hline Apgar score $<7$ at 5 minutes & 7 \\
\hline TTN & 6 \\
\hline Still birth & 2 \\
\hline NND & 2 \\
\hline Femur fracture & 1 \\
\hline Total & 22 \\
\hline
\end{tabular}

Transient tachypnea of newborn, Apgar score of $<7$ at 5 minutes, Meconium aspiration syndrome were the common complications seen. There were two still birth and two neonatal deaths in our study. Cause for neonatal death was fetal distress and cord prolapse, and cause of still birth was attributed to cord prolapse and transverse lie (Table 4).

Table 5: Cause of NICU admission.

\begin{tabular}{|ll|}
\hline Cause of NICU admission & Number \\
\hline Low Apgar score $<7$ at 5minutes & 7 \\
\hline Meconium aspiration syndrome & 4 \\
\hline TTN & 4 \\
\hline Femur fracture & 1 \\
\hline
\end{tabular}

Among the 183 caesarean sections 16 babies had neonatal ICU admissions. All cases were delivered by emergency CS. The most common indication for ICU admission was a low Apgar score at 5 mins followed by transient tachypnea of newborn and meconium aspiration syndrome (Table 5).

Table 6: Relationship of Apgar score $<7$ at 5 minutes with indication and category of CS.

\begin{tabular}{|c|c|c|c|}
\hline $\begin{array}{l}\text { Indication } \\
\text { of CS }\end{array}$ & $\begin{array}{l}\text { Emergency } \\
\text { CS indication }\end{array}$ & $\begin{array}{l}\text { Elective CS } \\
\text { indication }\end{array}$ & Total \\
\hline $\begin{array}{l}\text { Pre- } \\
\text { eclampsia }\end{array}$ & 1 & 0 & \\
\hline Fetal distress & 2 & 0 & \\
\hline $\begin{array}{l}\text { Placenta } \\
\text { Previa }\end{array}$ & 1 & 0 & \\
\hline IUGR & 2 & 0 & \\
\hline \multirow[t]{2}{*}{ CPD } & 1 & 0 & \\
\hline & $7 / 162$ & $0 / 21$ & $7 / 183$ \\
\hline
\end{tabular}

Fetal distress and IUGR were the most common association with a low Apgar score (Table 6).

\section{DISCUSSION}

The WHO statement (2015) on caesarean section concluded that caesarean sections are effective in saving maternal and infant lives but only when they are required for medically indicated reasons. ${ }^{10}$ Caesarean section is safe obstetric surgical procedure that contributes to reducing maternal and perinatal mortality and morbidity. Nevertheless, its advantages do not justify its continuous increase. $^{11}$

During the study period the caesarean section rate in NMCTH was found to be $21.40 \%$ which was similar to a previous study conducted in NMCTH $(22.30 \%)$ by Suwal et al. But the figure is significantly higher than that reported in $2002(9.4 \%)$ by Khanal. ${ }^{3,4}$

The CS rate in NMCTH was above the $15 \%$ recommended by WHO. This increasing trend of CS in NMCTH could be because NMCTH is a tertiary level hospital and a referral center for many other hospitals. The rise in caesarean section can also be attributed to caesarean section on maternal request, caesarean section done for breech presentation and no vaginal birth after caesarean section (VBAC) done at NMCTH.

Out of 183 women who underwent primary caesarean Section, $162(88.5 \%)$ cases were emergency and 21 $(11.5 \%)$ were elective. This correlates with study conducted in Norway where two third of the deliveries were emergency CS. ${ }^{12}$ This finding also correlates to a study performed in Ethiopia by Moges et al where $90.4 \%$ underwent emergency caesarean section. ${ }^{13}$

The main indication for primary caesarean section in women at NMCTH was fetal distress $(40.4 \%)$ which was seen in emergency CS. This high rate of could be due to increased use of electronic fetal monitoring but lack of fetal Scalp $\mathrm{pH}$ estimation. In a previous study done at NMCTH by Suwal et al, the most common indication of emergency CS was also fetal distress. ${ }^{3}$

Kolas et al concluded in a study conducted in Norway that most important indication was fetal distress accounting $21.9 \%$ of all indications. ${ }^{13}$ Kaur et al conducted a study in India in 2012 to determine the conditions behind fetal distress and found in their study that there was higher rate of caesarean section $(79.17 \%)$ in women with fetal distress. ${ }^{14}$

Emergency Caesarean section helps to reduce or control the effects of hypoxia and asphyxia on the fetus. It has been concluded by James that emergency caesarean section for fetal distress should be undertaken as quickly as possible, ideally within 30 minutes, but we shouldn't consider it as a poor obstetric care if it takes a few minutes longer. ${ }^{15}$ According to a study by Nelson et al, the false positive rate for the diagnosis is extremely high and arouse concern that if these indications were widely 
used, many cesarean sections would be performed without benefit and with potential for harm. ${ }^{16}$

In present study Cephalopelvic disproportion (CPD) accounted for $14.8 \%$ cases and is the second most common indication of caesarean section. CPD was seen exclusively in emergency CS. In a study conducted in Sweden by Stalberg et al, shows that narrow pelvic outlet increases the risk for caesarean section because of protracted labour. ${ }^{5}$

In a study by Moges et al, CPD accounted for $38.1 \%$ cases. ${ }^{13}$ The high incidence of CPD may be related to nutritional as well as genetic factors which attributes to the short stature and narrow pelvic inlet.

The third largest indication was Breech presentation accounting for $10.4 \%$ of total CS. $23.8 \%$ of CS was elective and $8.6 \%$ were emergency $\mathrm{CS}$ in this group. This indicates that more proportion of cases of Breech presentation underwent elective caesarean section in NMCTH. The remaining cases that underwent emergency caesarean section came in labor. This finding correlate with the trial done by Hannah et al, where Planned Caesarean section was found to be better than planned vaginal birth, for term fetus in the breech presentation due to its many neonatal complications. ${ }^{17}$

In our study, maternal complications occurred in 50 patients out of 183 patients. Out of which 47 cases were seen in emergency CS and only 3 cases were seen in elective CS. The most common complication encountered were urinary tract infection $(18.6 \%)$ followed by wound infection $(6.6 \%)$, postpartum hemorrhage $(1.6 \%)$ and caesarean hysterectomy $(0.5 \%)$.

UTI was seen in $18.6 \%$ cases in the total caesarean section. UTI was seen in $19.8 \%$ of emergency caesarean section as compared to $9.5 \%$ in elective caesarean section. This finding is similar to that seen in a study by Daniel $S$ in India at a semi-rural tertiary hospital where UTI in emergency CS was $27 \%$ and elective CS was $3.9 \% .^{18}$ This increased rate of UTI seen in emergency CS could be due to catheterization done in hurry under minimal aseptic conditions in emergency caesarean section. In a previous study by Suwal et al done at NMCTH, UTI was seen in $6.58 \%$ of emergency caesarean section compared to $2.29 \%$ elective caesarean section.

The high rate of UTI seen in CS could also be due to due to prolonged catheterization. All women who undergo CS at NMCTH are catheterized and catheter is removed the next post-operative day. Also, in some cases such as prolonged second stage of labour it is continued for longer period. Studies by El-Manzy et al have shown that there is lower risk of UTI among women who have immediate removal of catheter compared to delayed removal. ${ }^{19}$ Postpartum hemorrhage was seen in 3 cases $(1.85 \%)$ and all were emergency CS. In comparison to other studies the rate of PPH was low in this study. In a study conducted in USA in 1997 by Lu et al, PPH complicated $2.4 \%$ of live births. ${ }^{20}$

In a study at NMCTH by Suwal et al, PPH accounted for $2.99 \%$ in emergency compared to $6.89 \%$ in elective CS. In their study PPH was seen more in elective CS because the most common indication of elective CS was previous CS. But our study included only primary CS.

Wound infection was seen in $6.6 \%$ of cases of all caesarean sections in this study. It was found to be slightly higher in emergency CS $(6.8 \%)$ than elective CS $(4.8 \%)$. The higher rate of wound infection seen in emergency caesarean section could be due to abdominal painting done in hurry in cases of emergency CS and also the shorter interval between preoperative antibiotics given and caesarean section. In a previous study at NMCTH by Suwal et al $6.58 \%$ of wound infections were seen in emergency caesarean section and $3.44 \%$ were seen in elective CS. Our finding differs to that seen by Opiens et al where no difference in the rate of wound infection was seen between emergency and elective CS. ${ }^{21}$

There were total 22 cases with fetal complications. All complications were seen in emergency CS. Apgar score $<7$ at 5 minutes $3.8 \%$ was the most common complication followed by Meconium aspiration syndrome $2.2 \%$ and TTN $3.3 \%$.

In a previous study at NMCTH by Suwal et al, fetal complications in the form of Apgar Score $<6$ at 5 minutes in $9(5.38 \%)$ cases were seen in emergency CS. However, our finding does not correlate with that by Karlstrom et al where more respiratory complications were seen in elective CS compared to emergency $\mathrm{CS}^{22}$

There were 2 cases of still birth seen in this study all seen in emergency CS. The indications of still birth were cord prolapse and transverse lie. Neonatal death was seen two cases, indications for CS were fetal distress and cord prolapse. A study by O'Neill et al concluded that there is increase in unexplained stillbirth after CS compared to ND. ${ }^{23}$

Birth injury in the form of femur fracture was seen in 1 $(0.5 \%)$ case in emergency CS. Alexander and colleagues found in their study that fetal injury complicated 1 percent of cesarean deliveries and the lowest rate $0.5 \%$ was seen in the elective cesarean group. But this finding does not correlate with the study by Shah $\mathrm{G}$ et al, where the rate of birth trauma was found to be $6 / 1000 .^{24}$

In present study, 16 babies $(8.7 \%)$ had neonatal ICU (NICU) admission. All the 16 cases of NICU admissions were seen in emergency CS. Also seen in a study conducted by Kolas et al who found that compared with planned vaginal delivery, planned caesarean section increased the transfer rate to NICU from $5.2 \%$ to $9.8 \% .^{25}$ 


\section{CONCLUSION}

Emergency primary caesarean section was proportionally higher than elective caesarean section. It was also associated with more maternal and fetal complications. Therefore, it is important to understand the short-term and long-term benefit between caesarean and vaginal delivery, as well as safe and appropriate opportunities to prevent overuse of cesarean delivery, particularly primary cesarean delivery.

Funding: No funding sources Conflict of interest: None declared

Ethical approval: The study was approved by the Institutional Ethics Committee

\section{REFERENCES}

1. Neuman M, Alcock G, Azad K, Kuddus A, Osrin D, More N, et al. Prevalence and determinants of caesarean section in private and public health facilities in underserved South Asian communities: cross-sectional analysis of data from Bangladesh, India and Nepal. BMJ Open. 2014;4:e005982-e005982.

2. FHD/ NHSSP (Family Health Division). Responding to Increased Demand for Institutional Childbirths at Referral Hospitals in Nepal: Situational Analysis and Emerging Options. Department of Health Services. Ministry of Health Population. 2013.

3. Suwal A, Shrivastava VR, Giri A. Maternal and fetal outcome in elective versus emergency cesarean section. J Nepal Med Assoc. 2013;52:563-6.

4. Khanal R. Caesarean delivery at Nepal Medical College Teaching Hospital, Kathmandu, Nepal. Nepal Med Coll J. 2004;6:53-5.

5. Gibbons L, Belizan JM, Lauer JA, Betran AP, Merialdi $\mathrm{M}$, Althabe F. The Global numbers and costs of additionally needed and unneccessary cesarean sections performed per year: Overuse as barrier to universal coverage. World Health Report 2010. Background paper No 30, s. 1-32.WHO, Geneva;2010.

6. Gabbe SG, Niebyl JR, Simpson JL, Landon MB, Galan HL, Jauniaux ER, editors. obstetrics normal and problem pregnancies. $6^{\text {th }}$ ed. Philadelphia: Elsevier Saunders;2012.

7. James D, Streer PJ, Weiner CP, Gonik B, Crowther CA, Robson SC. (eds). High Risk Pregnancy Management Options. $4^{\text {th }}$ ed. Nottingham:Saunders;2011.

8. Alexander J, Leveno K, Hauth J, Landon M, Thom E, Spong $\mathrm{C}$ et al. Fetal Injury Associated With Cesarean Delivery. Obstet Gynecol. 2006;108:885-90.

9. Hansen AK, Wisborg K, Uldberg N, Henriksen TB. Risk of respiratory morbidity in term infants delivered by elective cesarean section: cohort study. Br Med J. 2008;336:85-7.

10. WHO statement on caesarean section rates. April 2015. WHO/RHR/15.02. Available at http://www.who.int/reproductivehealth/publications/mat ernal_perinatal_health/cs-statement/en/

11. Meloni A, Loddo A, Martsidis K, Deiana SF, Porru D, Antonelli A, et al. The role of caesarean section in modern obstetrics. J Pediatr Neonat Individual Med. 2012;1:53-8.

12. Kolas T, Hofoss D, Daltveit A, Nilsen S, Henriksen T, Hager $\mathrm{R}$ et al. Indications for cesarean deliveries in Norway. Am J Obstet Gynecol. 2003;188:864-70.

13. Moges A, Ademe BW, Akessa GM. Prevalence and outcome of caesarean section in Attat Hospital, Gurage Zone, SNNPR, Ethiopia. Arch Med. 2015;7(4):8.

14. Kaur J, Singh S, Kaur K. Current trend of caesarean sections and vaginal births. Adv in App Sci Res. 2013;4:196-202.

15. James D. Caesarean section for fetal distress. Br Med J. 2001;322:1316-7

16. Nelson KB, Dambrosia JM, Ting TY, Grether JK. Uncertain Value of electronic fetal monitoring in predicting cerebral palsy. N Engl J Med. 1996;334:6138.

17. Hannah ME, Hannah WJ, Hewson SA, Hodnett ED, Saigal S, Willan AR. Planned cesarean section versus vaginal birth for breech presentation at term: a randomized multicentre trial. Lancet. 2000;356:137583.

18. Daniel S, Viswanathan M, Simi BN, Naazeema A. Study of maternal outcome of emergency and elective caesarean section in semi-rural tertiary hospital. Nat $\mathrm{J}$ Med R. 2014;4:14-8.

19. El-Mazny A, El-Sharkawy M, Hassan A. A prospective randomized clinical trial comparing immediate versus delayed removal of urinary catheter following elective cesarean section. Eur J Obstet Gynecol Reprod Biol. 2014;181:111-4.

20. Lu MC, Fridman M, Korst LM, Gregory KD, Reyes C, Hobel CJ, et al. Variations in the incidence of postpartum hemorrhage across hospitals in California. Matern Child Health J. 2005;9:297-306.

21. Opoien HK, Valbo A, Grinde-Andersen A, Walberg M. Post-cesarean surgical site infections according to CDC standards: rates and risk factors. A prospective cohort study. Acta Obstet Gynecol Scand. 2007;86:1097-1102.

22. Karlström A, Lindgren H, Hildingsson I. Maternal and infant outcome after cesarean section without recorded medical indication: findings from a Swedish casecontrol study. Br J Obstet Gynecol. 2013;120:479-86.

23. O'Neill SM, Kearney PM, Kenny LC, Khashan AS, Henriksen TB, Lutomski JE et al. Cesarean delivery and subsequent stillbirth or miscarriage: Systematic review and meta-analysis. PLoS One. 2013;8:e54588.

24. Shah G, Freeman PAC, Cofrin K, Xu W. Cesarean deliveries and newborn injuries: evidence from linked utah birth certificate and inpatient discharge data. Utah's health: An Annual Rev. 2007;12:10-24.

25. Kolas T, Saugstad O D, Daltveit AK, Nilsen ST, Oian $P$. Planned cesarean versus planned vaginal delivery at term: Comparison of newborn infant outcomes. Am J Obstet Gynecol. 2006;195:1538-43.

Cite this article as: Rajbhandary S, Shrivastava VR. Study of indications and post-operative complications of primary caesarean section in tertiary care hospital in Nepal. Int J Reprod Contracept Obstet Gynecol 2018;7:835-40. 